\title{
Educação patrimonial e a dissolução das monoidentidades ${ }^{1}$
}

\section{Culture heritage education and the dissolution of mono-identities}

\author{
Rodrigo Manoel Dias da Silva
}

\begin{abstract}
RESUMO
O presente artigo objetiva compreender os sentidos atribuídos às políticas culturais brasileiras e seus empenhamentos pedagógicos, principalmente quanto à educação patrimonial. Por meio de uma análise sociológica, o autor aborda uma transição atinente às políticas e práticas de educação patrimonial, identificando um deslocamento em suas posições institucionais: de discursos monoidentitários, próprios do Nacionalismo Moderno, a processos políticos de reconhecimento e democratização cultural.

Palavras-chave: educação patrimonial; políticas culturais; identidade; reconhecimento.
\end{abstract}

\begin{abstract}
This paper aims at understanding meanings for Brazilian cultural policies and their pedagogical endeavour particularly as for culture heritage education. By means of a sociological analysis, the author addresses the transition on heritage policies and practices, identifying displacement in their institutional positions: from mono-identity discourses typical of the modern nationalism to political processes of cultural recognition and democratisation.
\end{abstract}

Keywords: culture heritage education; cultural policies; identity; recognition.

DOI: $10.1590 / 0104-4060.38374$

1 Apoio financeiro do Conselho Nacional de Desenvolvimento Científico e Tecnológico.

2 Universidade Federal da Fronteira Sul. Erechim, Rio Grande do Sul, Brasil. Campus Erechim. Av. Dom João Hoffmann, nº 313. Fátima. CEP: 99700-000. E-mail: rodrigoddsilva@ hotmail.com 


\section{Introdução}

Sob a égide do Estado Nacional, os processos identitários modernos foram delineados por interesses políticos de natureza territorial, linguística e simbólica. Diversas agências foram produzidas ou atualizadas com a finalidade de homogeneizar, padronizar ou fixar referências identitárias comuns a todos os cidadãos da nação, sendo notáveis, neste sentido, as intervenções da imprensa e dos meios de comunicação de massa, dos processos de escolarização e da definição de uma controversa política de bens culturais comprometida com a erudição e com o patriotismo.

O Estado Nacional europeu e, posteriormente, os latino-americanos orientaram suas ações a partir de uma representação monoidentitária, convencionada a partir de um conjunto de práticas que realizavam um "enquadramento" das memórias (POLLAK, 1989), tal como determinavam a concepção, o conteúdo e a implementação das políticas culturais de uma certa nação.

A educação patrimonial (Heritage Education), enquanto modalidade de intervenção pedagógica, surgiu inicialmente na Europa e acompanhou a tendência supracitada, uma vez que se comprometeu com políticas de conservação e administração de patrimônios históricos edificados, de interesse estatal. No Brasil, embora práticas similares sejam identificadas já na década de 1930, o termo emerge no fim dos anos de 1980 objetivando a conservação do patrimônio remanescente do período colonial e do caráter nacionalista da cultura brasileira.

O século XXI torna-se paisagem para o advento de um conjunto de mudanças atinentes às políticas culturais, nomeadamente: a intensificação das disputas por reivindicação identitária de atores e movimentos organizados; a influência de tendências culturais de natureza global (feminismo, ecologismo, etc.); a massificação cultural e a forte presença da mídia mundializada, sob os ditames do mercado econômico global; as intervenções de organismos internacionais em temáticas culturais; uma ressignificação dos sentidos atribuídos ao patrimônio e à patrimonialização.

Nesse contexto e, particularmente no caso brasileiro, sobretudo a partir da ascensão de Gilberto Gil ao Ministério da Cultura em 2003, verifica-se uma pluralização na agenda das políticas para o setor. Na esteira dessas mudanças, a educação patrimonial adquire relevância política na contemporaneidade, haja vista sua recorrência nos programas governamentais Mais Educação, Mais Cultura nas Escolas e Cultura Viva. (SILVA, 2013, 2014). Em termos sociológicos, as décadas passadas demonstraram a vigência de políticas culturais nacionalistas orientadas por processos monoidentitários, enquanto que, hoje, estas posições 
parecem deslocar-se para sentidos multi-identitários e democráticos, uma vez que afirmam, no plano de suas narrativas institucionais, a capacidade de incluir atores e grupos historicamente ausentes ou silenciados das/nas ações estatais.

O presente artigo pretende examinar esse suposto deslocamento, definido por Néstor Garcia Canclini (2006) como "dissolução das monoidentidades", e relacioná-lo às políticas e práticas de educação patrimonial desenvolvidas no Brasil.

\section{Identidade nacional, patrimônio e enquadramento da memória: leituras sociológicas}

O estabelecimento dos Estados Nacionais, na Modernidade, tornou a identidade um assunto de Estado. (CUCHE, 2002). A discussão sobre identidade nacional associa-se ao entendimento de "nação enquanto comunidade política imaginada" (ANDERSON, 2008) e, na mesma perspectiva, interpretada como produto cultural específico aproximando-se da discussão sobre "tradições inventadas". (HOBSBAWM, 2012). Na perspectiva de Eric Hobsbawm, entende-se por tradição inventada:

[...] um conjunto de práticas, normalmente reguladas por regras tácitas ou abertamente aceitas; tais práticas, de natureza ritual ou simbólica, visam inculcar certos valores e normas de comportamento a partir da repetição, o que implica, automaticamente, uma relação com o passado. Aliás, sempre que possível, tenta-se estabelecer continuidade com um passado histórico apropriado. (HOBSBAWN, 2012, p. 8).

Tal entendimento apresentado pelo historiador britânico oferece-nos elementos para considerarmos a produção das identidades nacionais. $\mathrm{Na} \mathrm{Mo}-$ dernidade, os modos pelos quais os indivíduos se reconhecem, se identificam e se apresentam no mundo social passam a estar condicionados pelos processos de formalização e de ritualização manifestos nestas tradições. Ou seja, por interesses na coesão social, na legitimação das instituições e nos processos de socialização, o Estado intervém nos processos individuais e coletivos de identificação. Neste sentido, Cuche (2002) menciona que o Estado moderno tende à monoidentificação, pois "a ideologia nacionalista é uma ideologia de exclusão das diferenças culturais". (CUCHE, 2002, p. 188). 
O mesmo autor identifica que:

\begin{abstract}
Nas sociedades modernas, o Estado registra de maneira cada vez mais minuciosa a identidade dos cidadãos, chegando em certos casos a fabricar carteiras de identidade "infalsificáveis". Os indivíduos e os grupos são cada vez menos livres para definir suas próprias identidades. (CUCHE, 2002, p. 188-189).
\end{abstract}

Assim, uma tendência à monoidentificação se multiplica pelas experiências de muitas sociedades contemporâneas, uma vez que a identidade coletiva é apresentada no singular, seja para si ou para os outros. (CUCHE, 2002). Esta situação, embora oriunda da emergência dos Estados Nacionais europeus, aproxima-se da realidade dos países da América Latina, principalmente a partir da conquista da Independência. Alguns estudos, inclusive, exploram a complexidade desses procedimentos que envolvem o advento dos meios de comunicação de massa, do desenvolvimento da cultura de massa, das políticas culturais e de entretenimento. (ORTIZ, 1988; CANCLINI, 1994; MARTÍN-BARBERO, 2009).

A tendência à monoidentificação é constituída por diversos processos sociológicos. Na análise que segue, apresentaremos três nuances de tais processos, a saber: as relações entre o Estado e a memória social, através do conceito de "enquadramento da memória" (POLLAK, 1989); a construção de políticas modernas de patrimonialização cultural e os usos da História (POULOT, 2009); e a fabricação da cidadania e da identidade nacional a partir de produções ideológicas, nos currículos, nas narrativas literárias ou nas formas escolares. (VIEIRA, 2009; DUBET, 2011).

Michael Pollak, sociólogo alemão, produziu pertinentes estudos acerca das relações entre as memórias coletivas e as ações do Estado. Segundo Pollak (1989), estudar as memórias coletivas fortemente constituídas, como as memórias nacionais, requer que primeiramente compreendamos suas funções. Neste sentido,

A memória, essa operação coletiva dos acontecimentos e das interpretações do passado que se quer salvaguardar, se integra, como vimos, em tentativas mais ou menos conscientes de definir e de reforçar sentimentos de pertencimento e fronteiras sociais entre coletividades de tamanhos diferentes: partidos, sindicatos, igrejas, aldeias, regiões, clãs, famílias, nações, etc. A referência ao passado serve para manter a coesão dos 
grupos e das instituições que compõem uma sociedade, para definir seu lugar respectivo, sua complementaridade, mas também as oposições irredutíveis. (POLLAK, 1989, p. 9).

Pollak, portanto, destaca a manutenção da coesão social e a defesa das fronteiras com outros grupos sociais como funções primordiais da memória nas sociedades modernas. Deste modo, a memória fornece um quadro de referências e de pontos de referência aos processos sociais experimentados por indivíduos e coletividades. Cada grupo, mediado por relações de poder e sua maior ou menor aproximação ao Estado Nacional, seleciona, justifica e socializa um determinado tipo de memória. $\mathrm{O}$ trabalho de enquadramento da memória aciona uma clivagem entre a memória nacional e as "memórias subterrâneas" - aquelas que foram silenciadas ou tornaram-se pouco perceptíveis pela memória oficial.

Esse trabalho de enquadramento da memória depende de um trabalho especializado.

O trabalho de enquadramento da memória se alimenta do material fornecido pela história. Esse material pode sem dúvida ser interpretado e combinado a um sem-número de referências associadas; guiado pela preocupação não apenas de manter as fronteiras sociais, mas também de modificá-las, esse trabalho reinterpreta incessantemente o passado em função dos combates do presente e do futuro. (POLLAK, 1989, p. 9-10).

O trabalho é tangenciado pela necessidade de justificação das ações e das práticas lembradas, assim como pela exigência de credibilidade. Neste sentido, fica evidente que "o que está em jogo na memória é também o sentido da identidade individual e do grupo". (POLLAK, 1989, p. 10). Ao mesmo tempo, tal empreendimento exige atores profissionalizados com a capacidade de operarem o controle da memória, seja sob a seleção de informantes e "testemunhas da história", ou pela definição de objetos materiais representativos de um olhar sobre as memórias.

Além da seleção das memórias, o Estado Nacional modulou representações materiais de seu poder e de seu controle sobre as identidades coletivas através da relação com o que se convencionou chamar de patrimônio. Poulot (2009), neste sentido, identifica a emergência moderna de uma "razão patrimonial no Ocidente". Tal racionalidade indica que o patrimônio passou a ocupar "uma posição privilegiada nas configurações da legitimidade cultural, nas reflexões 
sobre a identidade e nas políticas do vínculo social”. (POULOT, 2009, p. 199). A razão patrimonial desenvolveu procedimentos de conservação das heranças materiais e imateriais e de transmissão cultural como foros da consciência política nacional. Nas referidas circunstâncias, o imperativo de conservação impôs-se a diversas nações que passaram a implementar políticas patrimoniais em seus territórios.

Essa situação tem desenvolvido um consenso favorável à patrimonialização cultural e atualizado diversas lógicas e princípios das políticas culturais. Como consequência,

A atualidade impactante da patrimonialização parece ter impedido o questionamento a respeito da construção dessa forma de obrigação relativamente à presença material do passado. A afirmação de um ponto de vista contrário - a eventual recusa da patrimonialização ou sua contestação - é rapidamente estigmatizada, no debate público, com o termo "vândalo". (POULOT, 2009, p. 202).

O patrimônio parece ser visto como um presente do passado. A patrimonialização exige, pois, um empenho pedagógico pela transmissão dos valores, das simbolizações e das identidades mobilizadas. Comprometida com o nacional, enquanto comunidade imaginada (ANDERSON, 2008), a educação tornou-se uma prerrogativa das políticas patrimoniais, com preocupação conservacionista, mas também difusionista, em aproximações regulares entre a definição do patrimônio e a transmissão de elementos simbólicos consubstanciados a uma identidade nacional específica.

Um terceiro processo sociológico relevante nesta construção das identidades nacionais diz respeito à fabricação da cidadania, mediante a veiculação dos símbolos da pátria, cujo cerne discursivo centrou-se na erudição e no patriotismo. Liszt Vieira (2009, p. 65) observa que na construção da identidade nacional, na Europa e na América, foi privilegiado o sentimento de unidade, em detrimento da diversidade. Assim,

Tratava-se de construir a nação, o que foi feito oprimindo e sufocando identidades culturais, religiosas, étnicas, de gênero, etc., bem como a divisão da sociedade em classes. Enfim, o conceito de nação, baseado na unidade, ocultou a diversidade. (VIEIRA, 2009, p. 65). 
Essa ênfase, evidente na América Latina, engendrou ideologias, tais como a unificação linguística, o patriotismo e o nacionalismo, que forneceram subsídios para a formação das identidades nacionais e para a mobilização das populações para a defesa da pátria e de suas virtudes cívicas. Observa Vieira $(2009$, p. 65) que "é sugestivo que quase todos os hinos nacionais da América Latina falem em "morrer pela pátria"”. François Dubet (2011, p. 291) considera, sobre isso, que "as democracias nasceram nacionais e os cidadãos foram primeiramente patriotas".

A ideologia do nacionalismo esteve presente também na literatura, uma vez que a produção da nação implicava a veiculação de discursos que fortalecessem o imaginário nacional. (CANCLINI, 1994). A escola pública republicana operou a partir da mesma ideologização. O próprio Dubet esclarece essa dimensão no que tange à escolarização francesa, entretanto, é notável sua semelhança aos processos vividos no Brasil e na América.

A escola republicana ensina a história e a geografia da nação. Essa história mostra que a França é fruto de uma longa gestação para a qual todos os reis, todos os heróis, todos os grandes homens contribuíram pondo a sua pedra. Na escola, a história é sobretudo um relato do qual as crianças devem sentir-se herdeiras. A geografia preenche a mesma função; é preciso estar preparado para defender o solo sagrado. As grandes obras da cultura também participam dessa consciência nacional; todas as crianças aprendem de cor os mesmos poemas dos nossos grandes escritores: La Fontaine, Lamartine, Victor Hugo... Cada um deve compartilhar uma parte do panteão cultural nacional. (DUBET, 2011, p. 291).

A educação escolar coadunou-se aos interesses nacionalistas. Em boa medida, no Brasil, o enquadramento das memórias oficiais, a seleção do patrimônio material e a difusão dos valores e do "panteão cultural nacional" foram tarefas das instituições públicas de ensino, mesmo que não exclusivamente. Márcia Lopes dos Reis (1999), ao analisar as funções da educação escolar pública no Brasil e na América Latina, identifica práticas análogas às realizadas na Europa.

O conteúdo nacionalista e patriótico dos livros de textos escolares durante todo o período independente - inclusive no contexto brasileiro onde os livros de História das séries iniciais da educação básica traziam uma grande quantidade de heróis nacionais a partir dos quais eram descritos os fatos históricos - exemplificaram a conotação do projeto educacional com ênfase na formação do "espírito de nação". (REIS, 1999, p. 373). 
André Botelho (2002), por sua vez, estudando a obra "Através do Brasil", de Manoel Bomfim e Olavo Bilac, identificou o papel de reforma moral da sociedade depositado na educação brasileira no contexto da Primeira República. O programa de ação de diversos intelectuais brasileiros, até meados do século $\mathrm{XX}$, centrava-se no papel redentor da educação e da escola, mesmo que seus posicionamentos fossem contraditórios. De toda sorte, aqueles intelectuais estavam comprometidos com o objetivo de produzir uma nação e não qualquer nação, uma nação "à altura do século XX".

Na próxima seção, confrontaremos a relação entre educação e identidade nacional, diante dos diagnósticos de crise dos Estados Nação e da dissolução da monoidentidades. (CANCLINI, 2006).

\section{Educação e a dissolução das monoidentidades}

Alain Touraine (2007) observou que o Estado Nacional, em termos sintéticos, teve três funções principais:

[...] criar uma burocracia de Estado capaz de intervir no desenvolvimento econômico; exercer um controle sobre os costumes e os sentimentos, como o mostrou sobretudo Norbert Elias em seus estudos sobre a monarquia absoluta e especialmente sobre a Corte de Versalhes; fazer guerra, para constituir um território nacional ou defender-se contra ataques de Estados inimigos. (TOURAINE, 2007, p. 44).

Entretanto, por diversos fatores, a representação estável e forte dos Estados Nacionais declinou. A globalização econômica, os acordos econômicos regionais, a pulverização das relações de mercado, a mundialização da cultura, o terrorismo e o medo são hipóteses apontadas como decisivas para esse declínio. Novas ações administrativas foram exigidas e os Estados sofreram forte influência das racionalidades neoliberais. As ideologias nacionalistas esmaeceram sua força institucional.

Afora a multiplicidade de explicações para essas situações, Alain Touraine (2007) acrescenta que 
O papel de formação, de educação, mas também de controle moral e de repressão do Estado diminuiu sensivelmente, em parte das consequências dos progressos da ciência, em parte por causa das conquistas de um individualismo consumidor e hedonista. Em suma, o Estado nacional é bem menos do que antes um quadro geral de identificação coletiva. (TOURAINE, 2007, p. 44).

O sociólogo francês nos oferece argumentos para compreendermos alguns deslocamentos na relação entre o Estado e as identidades. Se os Estados do século XX orientaram-se pela homogeneização das identidades, hoje as tensões diversidade-homogeneidade adquirem maior consistência. (DOMINGUEZ, 2013). Essa fragilização nos dispositivos institucionais que plasmavam uma identidade nacional, desencadeou, por um lado, uma ampliação nos movimentos, nas disputas e demandas por reconhecimento cultural, e, de outro, uma acelerada inserção das culturas e das identidades nas tramas da sociedade de consumo.

No que tange às questões da cidadania, iniciou um conjunto de reações identitárias (CUCHE, 2002, p. 190), com ênfase nas ações de movimentos sociais a favor do "reconhecimento do outro". (TOURAINE, 2007). Há, ao mesmo tempo, uma maior abertura em relação à significativa transição da heteroidentificação à autoidentificação. Pois,

Todo o esforço das minorias consiste em se reapropriar dos meios de definir sua identidade, segundo seus próprios critérios, e não apenas em se reapropriar de uma identidade, em muitos casos concedida pelo grupo dominante. Trata-se então da transformação da hetero-identidade que é frequentemente uma identidade negativa em uma identidade positiva. (CUCHE, 2002, p. 190).

A fragilização da identidade nacional favoreceu também a emergência de movimentos que reivindicam identificações de modo extremista, caso do racismo, da xenofobia e dos novos fundamentalismos, assim como tensionamentos à capacidade das democracias para enfrentarem esses desafios. (WIEVIORKA, 2006).

Essa discussão, com efeito no começo do século XXI, fez-se paisagem para novas políticas para a escolarização e para a cultura. Tais políticas, associadas a uma ressignificação dos sentidos atribuídos ao patrimônio e à patrimonialização, evidenciaram os múltiplos agenciamentos identitários que circulam pelas insti- 
tuições de ensino e seu reconhecimento oficial. No caso brasileiro, os programas Cultura Viva, Mais Cultura nas Escolas e Mais Educação parecem acompanhar a referida tendência. (SILVA, 2013, 2014).

De outra parte, Canclini (2006) enfatiza a condição urbana e as contradições das culturas populares diante das formações sociais contemporâneas. Em primeiro lugar, o antropólogo recupera a hipótese do tensionamento entre o fortalecimento e a fragilização do controle estatal das identidades, sobretudo quanto às políticas culturais:

As políticas culturais eram concebidas até pouco tempo como conservação e administração de patrimônios históricos acumulados em territórios nitidamente definidos: os da nação, da etnia, da região ou da cidade. O Estado discernia entre o que deveria ou não ser apoiado segundo a fidelidade das ações ao território nativo e a um conjunto de tradições que distinguiam cada povo. Mais ainda: cada Estado-nação moderno assentou as tradições diversas e dispersas de etnias e regiões para que pudessem ser expostas harmonicamente nas vitrines dos museus nacionais e nos livros de texto, que continuam sendo idênticos em todas as zonas do país. (CANCLINI, 2006, p. 100).

E segue:

Sob esta estratégia unificadora, as diferenças culturais entre as cidades de um mesmo país eram assumidas como modos particulares dentro de um 'ser nacional' comum: as diferenças entre os portenhos e os provincianos, entre os paulistanos e os cariocas, entre os chilangos e os do interior pareciam material atraente para o folclore e o humor regionais, mas quase ninguém duvidava de que essas brigas entre irmãos fossem contidas pela profunda unidade de argentinos, brasileiros e mexicanos. (CANCLINI, 2006, p. 100).

Ou seja, a identidade nacional latino-americana elaborou-se sob a essencialista ideia de síntese, reafirmando a noção de monoidentidades. Todos os brasileiros seriam iguais. Todos os argentinos compartilhariam um sentimento coletivo comum. Os mexicanos se assemelhariam por modos de pertencimento e por uma história comum. Nos termos sociológicos de Michael Pollak, as 
identidades nacionais foram selecionadas e enquadradas na memória nacional, em detrimento da diversidade das culturas, identidades e biografias.

Porém,

Na segunda metade do século XX, esse simulacro das monoidentidades se torna inverossímil e explode, com particular evidência, nas grandes cidades. O que significa ser chilango numa cidade como a do México, onde mais da metade de seus habitantes nasceu em outras zonas do país? (CANCLINI, 2006, p. 101).

Além da crise do Estado Nação, a dissolução das monoidentidades pode ser atribuída ao crescimento urbano; às novas hierarquias de valores e aos novos padrões de consumo na globalização; à ação dos movimentos sociais que passaram a reivindicar a legitimação de identidades locais, de povos tradicionais e das culturas populares; aos processos migratórios nacionais e internacionais que têm modificado as feições dos países do continente.

A dissolução das monoidentidades impõe um conjunto de novos desafios à escolarização. Não que a escola já não fosse um espaço de circulação desta diversidade cultural, mas, agora, as narrativas institucionais veiculadas parecem ter se tornado mais permeáveis a tais expressões culturais ou identitárias. Seguramente esta permeabilidade não é homogênea ou harmônica, cada cotidiano escolar convive com contradições e relações de poder em diversas escalas, porém temos observado modificações na tessitura dos processos e das políticas institucionalizadas.

A identidade nacional brasileira veiculada na escola hodierna pouco se assemelha aos discursos nacionalistas da Era Vargas. Patrimônio nacional, memória, patriotismo ou cidadania encontram seus limites nos fazeres diários das escolas públicas brasileiras. Vejamos, a seguir, como esta discussão se expressa nas políticas para a educação patrimonial.

\section{Educação patrimonial e diversidade cultural no Brasil}

A educação patrimonial no Brasil, enquanto modalidade formativa voltada para a conservação do patrimônio histórico, cultural e artístico, surge no começo do século XX em decorrência da criação do Serviço do Patrimônio Histórico e 
Artístico Nacional. Embora sua denominação remeta à década de 1980, práticas de conscientização e defesa do patrimônio nacional estavam na agenda de Mário de Andrade e outros ilustres intelectuais brasileiros. A relação entre educação e patrimônio orientou-se pela construção imaginária do nacional (CANCLINI, 1994), reafirmando representações eurocêntricas de patrimônio, sobretudo a partir dos vestígios materiais remanescentes do período colonial.

A educação patrimonial surge em meio às discussões sobre a necessidade de se aprofundar o conhecimento, a conscientização e a preservação do patrimônio histórico e cultural. As primeiras ações designadas como educação patrimonial foram aplicadas no país a partir do "I Seminário de Uso Educacional de Museus e Monumentos", ocorrido em 1983 no Museu Imperial do Rio de Janeiro, a partir da tradução do termo anglófono Heritage Education. Desde então, a educação patrimonial assume um lugar de metodologia para o desenvolvimento de atividades pedagógicas na escola e em outros espaços sociais. No ano de 1999, foi publicado o "Guia Básico da Educação Patrimonial” para subsidiar os debates, os estudos e as práticas sobre a temática. O documento enfatizava que a educação patrimonial, quando ativa na sociedade, desperta sentimentos de pertencimento, o que só ocorreria mediante conhecimento e vivência, por isso as autoras enfatizavam que essa educação seria parte de um processo contínuo e sistemático.

$\mathrm{Na}$ ocasião, educação patrimonial foi definida como

[...] um instrumento de 'alfabetização cultural' que possibilita ao indivíduo fazer a leitura do mundo que o rodeia, levando-o à compreensão do universo sociocultural e da trajetória histórico-temporal em que está inserido. Este processo leva ao reforço da auto-estima dos indivíduos e comunidades e à valorização da cultura brasileira, compreendida como múltipla e plural. (HORTA; GRUNBERG; MONTEIRO, 1999, p. 6).

Desde a segunda metade do século XX, os processos de patrimonialização cultural foram influenciados pela Organização das Nações Unidas (UNESCO), mediante a difusão de documentos orientados por uma concepção antropológica de cultura, consolidados a partir da publicação da Recomendação sobre a Salvaguarda da Cultura Tradicional e Popular. (ABREU, 2015). A partir do início deste século, o reconhecimento da diversidade cultural passa a compor um conjunto de novas temáticas que têm problematizado as políticas para a escolarização na América Latina e no Brasil (ZAMBRANO, 2000; BOLÍVAR, 
2004; SILVA, 2010; DOMÍNGUEZ, 2012, 2013), mobilizado pela ideia de democratização cultural. (SILVA, 2013). Como observa Zambrano (2000):

\begin{abstract}
O reconhecimento da diversidade cultural na América latina modifica a percepção sobre sua própria realidade social e cultural. A transformação desta percepção é fonte, parte e resultado de uma mudança progressiva e conflitiva, desenvolvida de uma maneira complexa e multidimensional, com implicações não somente sobre os sujeitos envolvidos, mas uma redefinição na sociedade em seu conjunto. Na presente década, alguns frutos do reconhecimento da diversidade cultural saltam aos olhos sob a forma de adequações institucionais, reformas jurídicas, definição de políticas, elaboração de pressupostos e o surgimento de novas organizações e atores sociais. (ZAMBRANO, 2000, p. 149, tradução nossa).
\end{abstract}

Nessa reorganização institucional, o reconhecimento da diversidade cultural desencadeia diversas reflexões nos processos e políticas de escolarização, em diversas escalas. Diretrizes governamentais passam a considerar prerrogativas de direito a atores e grupos sociais historicamente ausentes nas plataformas governamentais, na mesma medida em que se intensificaram os movimentos de reivindicação à diversidade e de respeito à diferença. Assim, "[...] as demandas e afirmações culturais começam a dominar a cena política e cultural, com graves implicações para os currículos escolares, à ação educativa e à própria escola pública”. (BOLÍVAR, 2004, p. 17, tradução nossa). Segundo Regina Abreu (2015), neste contexto há uma tendência à "patrimonialização das diferenças", em que os próprios documentos da UNESCO enfatizam o enfrentamento à homogeneização protagonizada pelo capitalismo globalizado e a concessão de "especial atenção à noção de singularidade ou de especificidade local". (ABREU, 2015, p. 69).

Segundo Barbalho (2007), a partir da chegada de Lula à Presidência da República e, com ele, Gilberto Gil ao Ministério da Cultura, ocorreu uma reorientação das ações governamentais em cultura. Segundo o analista, "a preocupação da gestão Gilberto Gil está em revelar os brasis, trabalhar com as múltiplas manifestações culturais, em suas variadas matrizes étnicas, religiosas, de gênero, regionais, etc.". (BARBALHO, 2007, p. 52). Esta diretriz orientou a elaboração de novos programas governamentais e modificou os "empenhos pedagógicos" (POULOT, 2009) acerca das relações entre educação e patrimônio cultural. A educação patrimonial, nesta nova conjuntura, passa a ser agenciada por diversos objetivos sociais (YÚDICE, 2004), acompanhando cenários em 
que a cultura passa ser usada convenientemente em diversos projetos. Assim, diante do recrudescimento da diversidade cultural, a educação patrimonial tem sido integrada em iniciativas de educação turística, de desenvolvimento regional, de educação ambiental, etc.

Interessa-nos destacar, porém, suas modificações na plataforma das políticas estatais brasileiras, sobretudo a partir de sua incorporação como temática formativa no Programa Mais Educação ${ }^{3}$. A partir de uma análise do documento "Educação Patrimonial para o Programa Mais Educação" (BRASIL, 2012), verificamos que, no plano documental, há uma nova ênfase nas definições de educação patrimonial, assim como suas estratégias de intervenção são modificadas. Vejamos sua definição de educação patrimonial:

A educação patrimonial no Mais Educação propõe uma forma dinâmica e criativa da escola se relacionar com o patrimônio cultural de sua região e, a partir dessa ação, ampliar o entendimento dos vários aspectos que constituem o nosso patrimônio cultural e que isso tem a ver com a formação de cidadania, identidade cultural, memória e outras tantas coisas que fazem parte da nossa vida mas, muitas vezes, não nos damos conta do quão importante elas são. (BRASIL, 2012, p. 4).

A definição acima nos permite visualizar uma proposta educativa que relaciona educação escolar e patrimônio cultural, de modo plural. De certo modo, aponta para uma desnaturalização da ideia de patrimônio, já consagrada e constantemente associada a uma cultura de elite. Ao ampliar os sentidos de patrimônio, sugere que o estudante e o professor possam considerar sua comunidade, sua comunidade escolar, seu município, como elementos pertinentes para uma reflexão sobre suas identidades e para a construção da cidadania no cotidiano das instituições de ensino. $\mathrm{O}$ fragmento acima também permite que identifiquemos uma ampliação do conceito de patrimônio nacional, tal como pensado por Néstor Canclini (2006).

O documento aborda, em sua segunda metade, a educação patrimonial como forma de pesquisa da diversidade cultural presente na própria comunidade escolar, a partir da ideia de inventário. Assim,

3 O Programa Mais Educação é uma política do Ministério da Educação dirigida à ampliação da jornada escolar no ensino fundamental. É parte do Plano de Desenvolvimento da Educação (PDE) e foi criado pela Portaria Interministerial n ${ }^{\circ}$ 17/2007 e pelo Decreto $n^{\circ} 7083 / 2010$. 
Fazer um inventário é fazer um levantamento, uma lista descrevendo os bens que pertencem a uma pessoa ou a um grupo. Quando falamos em inventariar os bens culturais de um lugar ou de um grupo social, estamos falando em identificar suas referências culturais. (BRASIL, 2012, p. 11).

Como o documento foi elaborado em interlocução com o Instituto do Patrimônio Histórico e Artístico Nacional (IPHAN), a ideia de inventário foi inspirada nas práticas realizadas por esta entidade. O documento projeta a possibilidade de os estudantes tornarem-se pesquisadores da história, da memória e do patrimônio das comunidades onde residem. Neste aspecto, difere consideravelmente das definições de educação escolar mais consagradas no país, em particular na Era Vargas, quando os estudantes passaram a reproduzir versões oficiais da História e da Geografia nacional. (HILSDORF, 2011). Difere também do entendimento estritamente metodológico atribuído à educação patrimonial no começo dos anos de 1990, quando educação patrimonial acabou por assumir uma ênfase de conscientização dos estudantes para a salvaguarda das memórias e dos patrimônios. Tal interpretação permite o desvelar "das memórias subterrâneas" (POLLAK, 1989) e de suas contradições e conflitualidades.

Essas mudanças são orientadas por um movimento de "dissolução das monoidentidades" (CANCLINI, 2006), em que novas formas de apropriação política das memórias e dos patrimônios são articuladas a lutas por direitos sociais, por propriedade territorial e por cidadania. (ABREU, 2015). Os processos de patrimonialização de manifestações culturais indígenas, por exemplo, evidenciam essa dissolução pela complexidade com que são elaborados os dossiês e laudos técnicos utilizados em inventários de suas referências culturais, tendo em vista que exteriorizam processos identitários e reivindicações político-econômicas, da mesma forma que os próprios atores se tornam sujeitos ativos e politicamente engajados em tais processos. Assim, "os processos de patrimonialização deixaram de ser atributo de algumas falas autorizadas legitimadas no aparelho do Estado para se converterem em falas plurais tecidas em redes em que interagem diversos agentes". (ABREU, 2015, p. 72).

\section{Ainda é possível falarmos em educação patrimonial? - considerações finais}

Nesta análise, foi possível identificarmos alguns deslocamentos nos sentidos atribuídos às políticas culturais brasileiras e em seus empenhamentos 
pedagógicos, principalmente quanto à educação patrimonial. Considerando a definição clássica atribuída a esta modalidade de intervenção pedagógica, centrada em metodologias de ensino "conscientizadoras" e reprodutoras de representações fixistas de memória, de patrimônio e de identidade, o cenário contemporâneo parece descaracterizá-la. A educação patrimonial não é mais a mesma. Ainda é possível falarmos em educação patrimonial?

Provavelmente, sim. Porém, sua permanência na agenda das políticas para a cultura e para a escolarização depende das novas significações e novos objetivos sociais que os atores, individual e coletivamente, venham a depositar-lhe. Estão em curso, por certo, processos de "reenquadramento da memória", em que negros, indígenas, mulheres e diversos outros coletivos vêm negociando o reconhecimento oficial de suas histórias e identidades e sua incorporação nas lógicas político-institucionais. Esse reenquadramento, tal como o enquadramento (POLLAK, 1989), depende da interpretação das memórias sociais como objeto de disputa e da capacidade dos atores para sustentar sua legitimidade e suas múltiplas reivindicações.

Por fim, podemos concluir que as políticas culturais democraticamente orientadas são concebidas a partir da dissolução das monoidentidades (CANCLINI, 2006), uma vez que se demonstram permeáveis às mudanças sociais, políticas e culturais de seu tempo. Porém, os fios que costuram a transição analítica de políticas culturais elaboradas em processos monoidentitários para situações em que são orientadas por processos de reconhecimento e democratização sociocultural (multi-identitários) ainda estão demasiado frouxos.

\section{REFERÊNCIAS}

ABREU, R. Patrimonialização das diferenças e os novos sujeitos de direito coletivo no Brasil. In: TARDY, C.; DODEBEI, V. (Orgs.). Memória e novos patrimônios. Marseille: Open Edition Press, 2015. p. 67-93.

ANDERSON, B. Comunidades imaginadas: reflexões sobre a origem e a difusão do nacionalismo. São Paulo: Companhia das Letras, 2008.

BARBALHO, A. Políticas culturais no Brasil: identidade e diversidade sem diferença. In: RUBIM, A. A. C. (Org.). Políticas culturais no Brasil. Salvador: Ed. UFBA, 2007. p. 37-60.

BOLÍVAR, A. Ciudadanía y escuela publica en el contexto de diversidad cultural. Revista Mexicana de Investigación Educativa, México, n. 20, v. 9, p. 15-38, jan./abr. 2004. 
BOTELHO, A. Aprendizagem do Brasil: a nação em busca dos seus portadores sociais. Campinas: Ed. Unicamp, 2002.

BRASIL. Educação Patrimonial para o Programa Mais Educação. Brasília: Ministério da Educação, 2012.

CANCLINI, N. G. Consumidores e Cidadãos: conflitos multiculturais da globalização. 6. ed. Rio de Janeiro: Ed. UFRJ, 2006.

CANCLINI, N. G. O patrimônio cultural e a construção imaginária do nacional. Revista do Patrimônio Histórico e Artístico Nacional, Brasília, n. 23, p. 95-115, 1994.

CUCHE, D. A noção de cultura nas ciências sociais. Bauru: Edusc, 2002.

DOMINGUEZ, J. B. Educación intercultural: ¿Trabajar con los diferentes o las diferencias? Revista Ra Ximhai, México, v. 9, n. 1, p. 61-73, jan./abr. 2013.

DOMINGUEZ, J. B. La educación en el contexto de la diversidad. Educação em foco, v. 17, n. 1, p. 21-42, mar./jun. 2012.

DUBET, F. Mutações cruzadas: a cidadania e a escola. Revista Brasileira de Educação, v. 16, n. 47, p. 289-305, maio/ago. 2011.

HOBSBAWN, E. Introdução: A invenção das tradições. In: HOBSBAWN, E.; RANGER, T. (Orgs). A invenção das tradições. São Paulo: Paz e Terra, 2012. p. 7-25.

HILSDORF, M. L. História da Educação Brasileira: leituras. São Paulo: Cengage Learning, 2011.

HORTA, M. L.; GRUNBERG, E.; MONTEIRO, A. Guia Básico de Educação Patrimonial. Brasília: IPHAN, 1999.

MARTÍN-BARBERO, J. Dos meios às mediações: comunicação, cultura e hegemonia. 6. ed. Rio de Janeiro: Ed. UFRJ, 2009.

ORTIZ, R. A Moderna Tradição Brasileira: Cultura Brasileira e Indústria Cultural. São Paulo: Brasiliense, 1988.

POLLAK, M. Memória, esquecimento, silêncio. Estudos Históricos, Rio de Janeiro, v. 2, n. 3, p. 3-15, jan. 1989.

POULOT, D. Uma história do patrimônio no ocidente - séculos XVIII-XXI: do monumento aos valores. São Paulo: Estação Liberdade, 2009.

REIS, M. Uma nova leitura da função social da escola no processo de formação da nação na América Latina. Sociedade e Estado, Brasília, v. 14, n. 2, p. 369-390, jul./dez. 1999.

SILVA, R. M. D. Educação, cidadania e agenciamentos formativos nas políticas culturais brasileiras. Educação \& Sociedade, Campinas, v. 35, n. 127, p. 397-415, abr./jun. 2014.

SILVA, R. M. D. Narrativas de democratização cultural no Brasil: um olhar sociológico ao Programa Cultura Viva. Revista Ciências Sociais Unisinos, São Leopoldo, v. 49, n. 3, p. 269-278, set./dez. 2013. 
SILVA, R. M. D. Os direitos culturais e a política educacional brasileira na contemporaneidade. Revista Brasileira de Política e Administração da Educação, Porto Alegre, v. 26, n. 1, p. 123-136, jan./abr. 2010.

TOURAINE, A. Um novo paradigma para compreender o mundo de hoje. São Paulo: Vozes, 2007.

VIEIRA, L. Morrer pela pátria? Notas sobre identidade nacional e globalização. In: VIEIRA, L. (Org.). Identidade e globalização: impasses e perspectivas da identidade e da diversidade cultural. Rio de Janeiro: Record, 2009. p. 61-85.

WIEVIORKA, M. Em que mundo viveremos? São Paulo: Perspectiva, 2006.

YÚDICE, G. A conveniência da cultura: usos da cultura na era global. Belo Horizonte: Ed. UFMG, 2004.

Texto recebido em 23 de outubro de 2014. Texto aprovado em 10 de junho de 2015. 